\title{
Article \\ Reconsidering the Use of the Mindset Assessment Profile in Educational Contexts
}

\author{
Alexander P. Burgoyne ${ }^{1, *(D)}$ and Brooke N. Macnamara ${ }^{2}$ \\ 1 School of Psychology, Georgia Institute of Technology, 654 Cherry St., Atlanta, GA 30332, USA \\ 2 Department of Psychological Sciences, Case Western Reserve University, 11220 Bellflower Road, Cleveland, \\ OH 44106-7123, USA; bnm24@case.edu \\ * Correspondence: burgoyn4@gmail.com
}

check for

updates

Citation: Burgoyne, Alexander P., and Brooke N. Macnamara. 2021. Reconsidering the Use of the Mindset Assessment Profile in Educational Contexts. Journal of Intelligence 9: 39. https://doi.org/10.3390/ jintelligence 9030039

Received: 28 May 2021

Accepted: 30 July 2021

Published: 4 August 2021

Publisher's Note: MDPI stays neutral with regard to jurisdictional claims in published maps and institutional affiliations.

Copyright: (c) 2021 by the authors. Licensee MDPI, Basel, Switzerland. This article is an open access article distributed under the terms and conditions of the Creative Commons Attribution (CC BY) license (https:// creativecommons.org/licenses/by/ $4.0 /)$.

\begin{abstract}
The Mindset Assessment Profile is a popular questionnaire purportedly designed to measure mindset-an individual's belief in whether intelligence is malleable or stable. Despite its widespread use, the questionnaire appears to assess an individual's need for cognition and goal orientation more than mindset. We assessed the reliability, construct validity, and factor structure of the Mindset Assessment Profile in a sample of 992 undergraduates. The reliability of the Mindset Assessment Profile was questionable $(\alpha=.63)$ and significantly lower than the reliability of the Implicit Theories of Intelligence Questionnaire $(\alpha=.94)$, an established measure of mindset. The Mindset Assessment Profile also lacked convergent and discriminant validity. Overall scores on the Mindset Assessment Profile correlated significantly more strongly with need for cognition than with mindset. Item-level analyses supported this finding: most items correlated weakly or not at all with mindset, and correlated significantly more strongly with need for cognition and learning goal orientation. Exploratory factor analysis indicated that three factors were underlying scores on the Mindset Assessment Profile: need for cognition, mindset, and performance goal orientation. Based on its questionable reliability and poor construct validity, we do not recommend that researchers and educators use the Mindset Assessment Profile to measure mindset.
\end{abstract}

Keywords: mindset; implicit theories; mindset assessment profile; validity; reliability

\section{Reconsidering the Use of the Mindset Assessment Profile in Educational Contexts}

Mindset refers to people's beliefs about the nature of their abilities. People with a growth mindset believe that attributes such as intelligence can be developed, whereas people with a fixed mindset believe that these attributes are stable. Some researchers have argued that a growth mindset is beneficial for academic achievement, on the premise that students with a growth mindset will pursue challenges and be resilient to setbacks (Blackwell et al. 2007). However, recent empirical evaluations have revealed only weak evidence for most of mindset's premises, including its relationships with goal orientation, pursuit of challenges, resilience to setbacks, and academic achievement (Burgoyne et al. 2020; Li and Bates 2019; Payne et al. 2007; Sisk et al. 2018). Nevertheless, educators frequently use growth mindset interventions to encourage students to adopt a growth mindset in an effort to improve their academic performance (Boaler 2013; Sisk et al. 2018).

Mindset interventions are a booming industry in the educational sector. For example, the for-profit company Mindset Works has sold growth mindset interventions products to parents, teachers, and schools for over a decade (https://www.mindsetworks.com/ programs/ (accessed on 6 April 2021)). Included in these intervention programs is an eight-item measure- the Mindset Assessment Profile-which is used as a diagnostic tool to determine whether students have a growth or fixed mindset; that is, whether they believe intelligence is malleable or stable (Hall 2016; Thomas 2018). The Mindset Assessment Profile questionnaire is also provided on the company's website, where visitors are encouraged to "Take the Mindset Assessment to Learn More About Your Mindset." 
(http:/ /blog.mindsetworks.com/what-s-my-mindset (accessed on 6 April 2021)). As a result, researchers and educators frequently administer the Mindset Assessment Profile to measure mindset in educational contexts (see, e.g., Bedford 2017; Cartwright and Hallar 2018; Hall 2016; Lim et al. 2020; Neufville 2019; Saia 2017; Thomas 2018; Wakefield 2019; Wolferd 2020). Often, the Mindset Assessment Profile is administered before and after an intervention to test whether it altered students' mindsets. A change from pre- to post-intervention is taken as evidence that the intervention was successful (Bedford 2017; Cartwright and Hallar 2018; Saia 2017; Thomas 2018; Wolferd 2020), a point we return to in the Discussion.

Given the Mindset Assessment Profile's extensive use among researchers, educators, and students, the psychometric qualities of this scale have practical significance. Although Mindset Works describes the Mindset Assessment Profile as a "diagnostic tool drawn from research-validated measures" (http:/ /blog.mindsetworks.com/what-s-my-mindset (accessed on 6 April 2021)), they do not provide any information on the reliability, construct validity, or factor structure of the scale.

\section{Present Study}

We noticed that many items in the Mindset Assessment Profile appeared to be tapping constructs other than mindset, namely goal orientation-one's drive to master new material and demonstrate competency (Elliot and Church 1997), and need for cognition-one's tendency to engage in and enjoy thinking (Cacioppo and Petty 1982). If this is the case, students, teachers, and parents may have a misconstrued understanding of their mindset based on their Mindset Assessment Profile scores.

According to mindset theory, goal orientations are related to one's mindset of intelligence, but they are distinct constructs (Dweck and Leggett 1988). That is, individuals with a growth mindset are hypothesized to endorse learning goals, reflecting a desire to acquire new skills, whereas people with a fixed mindset are hypothesized to endorse performance goals, reflecting a desire to prove their abilities (or not demonstrate a lack of ability). Despite these claims, however, evidence suggests that mindset is only weakly related to goal orientation. For example, in a sample of 438 undergraduate students, Burgoyne et al. (2020) found that mindset was weakly correlated with learning goal orientation $(r=.10)$ and performance goal orientation $(r=-.11)$, and Payne et al. (2007) found correlations of a similar magnitude in meta-analytic work. In light of their results, Payne et al. (2007) concluded that the relationship between mindset and goal orientation had been overstated by proponents of mindset theory: “Contrary to Dweck's (1986) perspective, the effect sizes were very small, providing little evidence for Dweck's (1986) view that implicit theories are the primary underlying antecedent of GO [goal orientation]" (p. 140).

Need for cognition, on the other hand, is a relatively unexplored construct within mindset's nomological network. At a conceptual level, one might expect that individuals with more of a growth mindset would rate higher on need for cognition. That is, mindset theory would likely predict that individuals with a growth mindset would enjoy mental challenges, such as thinking about complex problems, on the basis that they might learn from them. The empirical evidence for this relationship is scarce, but suggests a weak correlation. For example, Birney et al. (2018) found that growth mindset correlated $r=.12$ with need for cognition in a sample of 142 experienced business managers.

A related concern is that researchers using the Mindset Assessment Profile may make inaccurate assumptions about the relationship between mindset and measured outcomes (e.g., academic achievement) if the Mindset Assessment Profile includes items measuring other non-mindset constructs. For instance, if Mindset Assessment Profile scores are contaminated by the inclusion of goal orientation items, the observed relationship between Mindset Assessment Profile scores and goal orientation will be exaggerated. As another example, if goal orientation and need for cognition are stronger predictors of academic achievement than mindset is, then the relationship between Mindset Assessment Profile 
scores and academic achievement will be artificially inflated due to the inclusion of items tapping these constructs.

Analyses

The purpose of this study was to assess the internal consistency reliability, construct validity, and factor structure of the Mindset Assessment Profile as a measure of mindset. We estimated the internal reliability of the Mindset Assessment Profile by computing Cronbach's alpha ( $\alpha$; Cronbach 1951; see George and Mallery 2003, for rules of thumb for interpreting Cronbach's alpha) and McDonald's omega coefficient ( $\omega ;$ McDonald 1999; McNeish 2018; Zinbarg et al. 2005). Cronbach's alpha tests for consistency among items within a measure, and McDonald's omega indicates the proportion of variance in the scale scores accounted for by a single factor (Zinbarg et al. 2005).

Construct validity is the degree to which a measure's variance is attributable to variance in the construct it is intended to measure rather than some other factor $\left(\mathrm{O}^{\prime}\right.$ 'LearyKelly and Vokurka 1998). Construct validity is evaluated in terms of convergent and discriminant validity. Convergent validity is the degree to which different measures designed to assess the same construct correlate with one another (Cunningham et al. 2001): measures of the same construct should be strongly related. We tested for convergent validity by correlating scores on the Mindset Assessment Profile with a well-established measure of mindset, Dweck's (2000) Implicit Theories of Intelligence Questionnaire, which has been shown to have sound psychometric properties (Dweck 2000). Discriminant validity, on the other hand, refers to the extent to which measures designed to assess different constructs correlate with one another (Campbell and Fiske 1959). Compared with two measures assessing the same construct, measures designed to assess different constructs should be more weakly correlated. We tested for discriminant validity by correlating scores on the Mindset Assessment Profile with measures of need for cognition and goal orientation.

Finally, we conducted an exploratory factor analysis on the items in the Mindset Assessment Profile to assess its factor structure. If all or most items load well onto a single factor, this suggests the Mindset Assessment Profile is measuring a single personality construct. If items load better on multiple factors, this suggests multiple personality constructs are underlying scores on this measure.

\section{Method}

Methods were pre-registered at https:/ / osf.io/N82F4/.

\subsection{Participants}

The participants were 998 undergraduate students at Michigan State University, ranging in age from 18 to $31(M=19.73, S D=1.48)$. Approximately $63 \%$ of the participants were female. Around $38 \%$ of the participants were in their first year of college, $28 \%$ were in their second year, $21 \%$ were in their third year, and the remaining $13 \%$ were in their fourth or fifth year. Six participants were excluded because they did not reach the end of the survey, leaving a final sample of 992 participants. Missing data $(<1 \%$ of cases) were handled using listwise deletion on an analysis-by-analysis basis. With 992 participants, we had $89 \%$ power to detect significant correlations of $r \geq .10$ (Faul et al. 2007). All participants provided informed consent and received partial course credit for their participation in the study.

\subsection{Measures}

Demographics. Participants were asked to report their age, year in college, and gender.

Mindset Assessment Profile. Participants responded to the eight items in the Mindset Assessment Profile taken from the Mindset Works website (http://blog.mindsetworks. com/what-s-my-mindset (accessed on 6 April 2021)) using a six-point Likert scale ranging from "Disagree a lot" to "Agree a lot." The items are listed in order of administration: (1) "No matter how much intelligence you have, you can always change it a good deal"; 
(2) "You can learn new things, but you cannot really change your basic level of intelligence";

(3) "I like my work best when it makes me think hard"; (4) "I like my work best when I can do it really well without too much trouble"; (5) "I like work that I'll learn from even if I make a lot of mistakes"; (6) "I like my work best when I can do it perfectly without any mistakes"; (7) "When something is hard, it just makes me want to work more on it, not less"; and (8) "To tell the truth, when I work hard, it makes me feel as though I'm not very smart." Even numbered items were reverse scored. The final score was the mean response to the items.

Mindset. Participants completed Dweck's (2000) Implicit Theories of Intelligence Questionnaire as a measure of mindset. Participants responded to eight items using a seven-point Likert scale, rating the degree to which they agreed or disagreed with each statement: (1) "You have a certain amount of intelligence, and you can't really do much to change it"; (2) "No matter who you are, you can significantly change your intelligence level"; (3) "Your intelligence is something about you that you can't change very much"; (4) "You can always substantially change how intelligent you are"; (5) "To be honest, you can't really change how intelligent you are"; (6) "No matter how much intelligence you have you can always change it quite a bit"; (7) "You can learn new things, but you can't really change your basic intelligence"; and (8) "You can change even your basic intelligence level considerably." Odd numbered items were reverse scored. The response options ranged from "Strongly agree" to "Strongly disagree." The final score was the mean response to the items. Higher scores on this measure correspond to more of a growth mindset, reflecting the belief that intelligence is malleable. Lower scores correspond to more of a fixed mindset, reflecting the belief that intelligence is stable.

Need for Cognition. Participants completed Cacioppo et al.'s (1984) Need for Cognition Questionnaire. Participants responded to eighteen items using a seven-point Likert scale, rating the degree to which they agreed or disagreed with statements such as "I would prefer complex to simple problems" and "Thinking is not my idea of fun" (reverse scored). The response options ranged from "Strongly agree" to "Strongly disagree." The final score was the mean response to the items. Higher scores correspond to greater need for cognition.

Goal Orientation. Participants completed an adapted version of Elliot and Church's (1997) Goal Orientation Questionnaire. Participants responded to sixteen items using a seven-point Likert scale ranging from "Disagree a lot" to "Agree a lot." This questionnaire assesses three goal orientations: learning goal orientation, performance approach goal orientation, and performance avoidance goal orientation. Participants rated the degree to which they agreed or disagreed with learning goal statements such as "I want to learn as much as possible," performance approach goal statements such as "I strive to demonstrate my ability relative to others," and performance avoidance goal statements such as "I worry about the possibility of performing poorly." The final score for each goal orientation was the mean response to the items. Higher scores correspond to greater endorsement of each goal orientation.

Procedure. Participants completed the questionnaires online on Qualtrics. Participants were first presented with the three-item demographic questionnaire. The order of the remaining questionnaires was randomized across participants to control for potential order effects.

\section{Results}

Analyses were preregistered at https://osf.io/N82F4/ and were conducted using SPSS. Data are openly available at https:/ / osf.io/N82F4/.

\subsection{Reliability of the Mindset Assessment Profile}

Descriptive statistics are presented in Table 1 and distributions are presented in Figure 1. Of the questionnaires administered to participants, the Mindset Assessment Profile had the lowest reliability $(\alpha=.63, \omega=.61)$. Table A1 in the Appendix A presents the inter-item correlations for the Mindset Assessment Profile. The correlations between 
the items varied in absolute magnitude from $r=.05$ to $r=.49$. Compared to the Mindset Assessment Profile, the Implicit Theories of Intelligence Questionnaire ("Mindset" in Table 1) had excellent reliability $(\alpha=.94, \omega=.94)$. Indeed, the Mindset Assessment Profile had a significantly lower Cronbach's alpha reliability estimate than the Implicit Theories of Intelligence Questionnaire, $t=38.89, p<.001$ (Abd-El-Fattah and Hassan 2011). The other questionnaires had acceptable to good reliability, ranging from $\alpha=.72$ to $\alpha=.87$ ( $\omega$ also ranged from .72 to .87$)$.

Table 1. Descriptive statistics.

\begin{tabular}{lcccccccc}
\hline Measure & Items & $N$ & $M$ & $S D$ & Skew & Kurtosis & $\alpha$ & $\omega$ \\
\hline Mindset Assessment Profile & 8 & 992 & 3.70 & 0.62 & 0.11 & -0.02 & .63 & .61 \\
Mindset & 8 & 992 & 4.72 & 1.26 & -0.31 & -0.28 & .94 & .94 \\
Need for cognition & 18 & 991 & 4.37 & 0.79 & 0.08 & 0.46 & .87 & .87 \\
Learning goal orientation & 5 & 991 & 5.48 & 0.84 & -0.45 & 0.30 & .78 & .78 \\
Performance approach goal orientation & 6 & 991 & 4.96 & 1.07 & -0.42 & -0.07 & .85 & .86 \\
Performance avoidance goal orientation & 5 & 991 & 5.39 & 0.98 & -0.62 & 0.15 & .72 & .72 \\
\hline
\end{tabular}

Note. "Mindset" refers to the Implicit Theories of Intelligence Questionnaire.

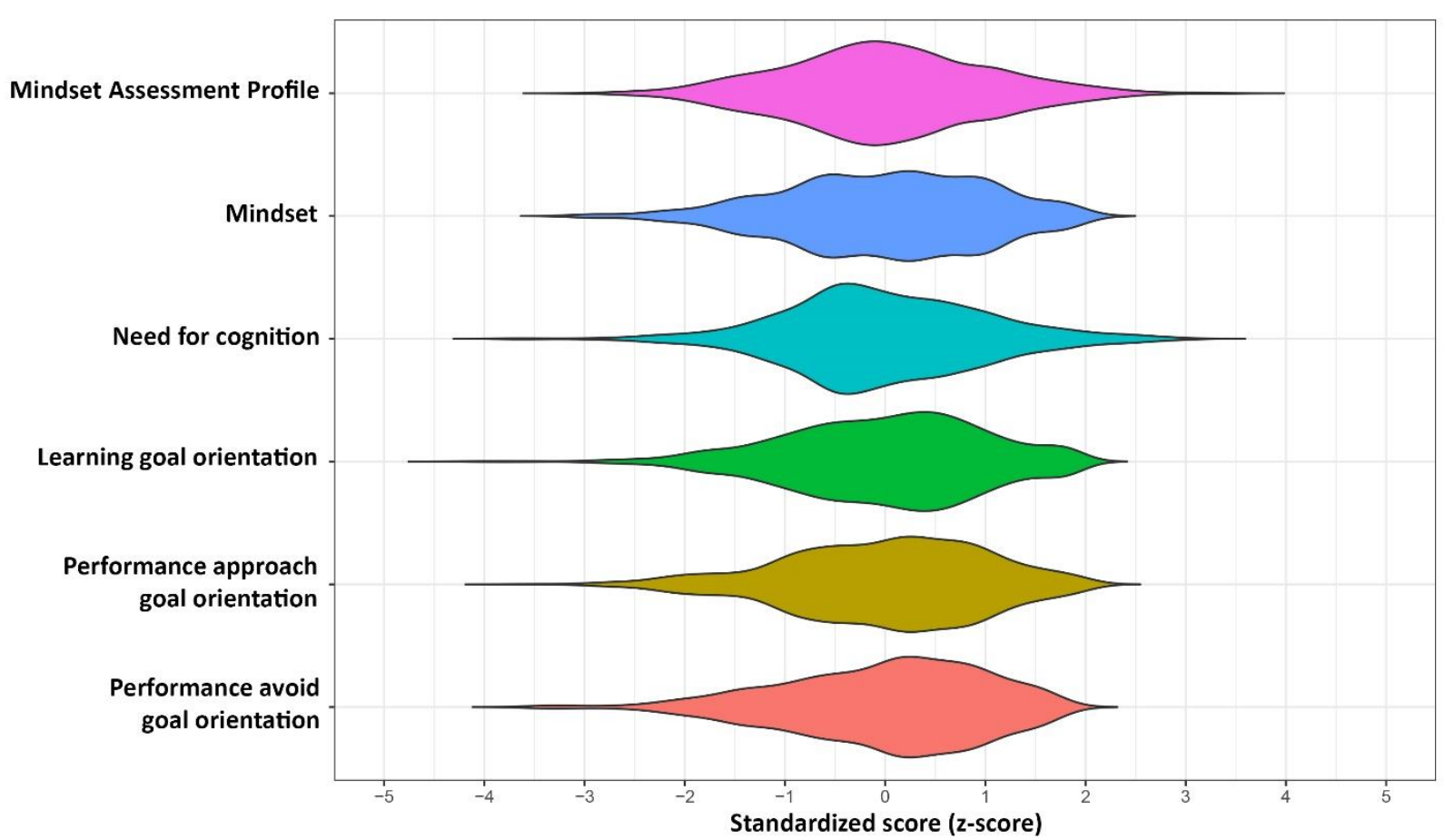

Figure 1. Distribution of standardized scores (i.e., z-scores) on each measure. Note: "Mindset" refers to the Implicit Theories of Intelligence Questionnaire.

\subsection{Construct Validity of the Mindset Assessment Profile}

Correlations between measures are presented in Table 2. Scatterplots depicting the relationships between the Mindset Assessment Profile and the other measures (upper row) and between the Implicit Theories of Intelligence Questionnaire and the other measures (bottom row) are presented in Figure 2. Scores on the Mindset Assessment Profile correlated most strongly with need for cognition $(r=.59,95 \%$ CI [.55, .63], $p<.001)$, followed by mindset $(r=.50,95 \% \mathrm{CI}[.45, .55], p<.001)$ and learning goal orientation $(r=.48,95 \% \mathrm{CI}$ $[.43, .53], p<.001)$. Steiger's (1980) test for the difference between dependent correlations revealed that the correlation between the Mindset Assessment Profile and need for cognition was significantly stronger than the correlation between the Mindset Assessment Profile and mindset, $z=2.87, p=.004$. This indicates that the Mindset Assessment Profile lacks construct validity due to poor discriminant validity. Scores on the Mindset Assessment 
Profile were more closely related to need for cognition than mindset. For comparison, mindset as measured by the Implicit Theories of Intelligence Questionnaire correlated only weakly with need for cognition $(r=.18,95 \%$ CI $[.12, .24], p<.001)$; see Figure 2.

As an additional test of convergent and discriminant validity, we computed correlations between each of the items in the Mindset Assessment Profile and the other personality measures. ${ }^{1}$ The purpose of this analysis was to understand which items in the Mindset Assessment Profile correlated more strongly with non-mindset constructs than with mindset.

As shown in Table 3, most of the items in the Mindset Assessment Profile correlated more strongly with need for cognition and learning goal orientation than with mindset. Only items one and two correlated strongly with mindset $(r=.70,95 \%$ CI [.67, .73], $p<.001$ and $r=.71,95 \% \mathrm{CI}[.68, .74], p<.001$, respectively). This is not surprising, as the wording of these items is nearly identical to the wording of items six and seven in the Implicit Theories of Intelligence Questionnaire.

By contrast, items three, four, five, six, seven, and eight from the Mindset Assessment Profile correlated significantly more strongly with need for cognition (average $r=.38$ ) than with mindset (average $r=.12$ ); Steiger's test for the difference between dependent correlations revealed zs ranging from 3.32 to 11.96 , all $p s<.001$. Items three, four, five, six, seven, and eight from the Mindset Assessment Profile also correlated significantly more strongly with learning goal orientation (average $r=.29$ ) than with mindset (average $r=.12$ ); Steiger's $z$ s ranged from 2.07 to 9.90 , all $p s<.02$. Items four and six from the Mindset Assessment Profile did not correlate significantly with mindset $(r \mathrm{~s}=-.01,95 \%$ CIs $[-.07, .05], p s>.65)$.

These results indicate that most of the items in the Mindset Assessment Profile lack both convergent and discriminant validity. Most items correlated weakly or not at all with mindset, and correlated significantly more strongly with need for cognition and learning goal orientation than with mindset. A correlation matrix with the items from all the personality scales is presented on the Open Science Framework: https:/ / osf.io/N82F4/.

Table 2. Correlation matrix.

\begin{tabular}{lccccc}
\hline Personality Measure & $\mathbf{1}$ & $\mathbf{2}$ & $\mathbf{3}$ & $\mathbf{4}$ & $\mathbf{5}$ \\
\hline (1) Mindset Assessment Profile & - & & & & \\
(2) Mindset & $\mathbf{. 5 0}$ & - & & & \\
(3) Need for cognition & $\mathbf{. 5 9}$ & $\mathbf{. 1 8}$ & - & & \\
(4) Learning goal orientation & .48 & .21 & .58 & - & \\
(5) Performance approach goal orientation & -.03 & -.09 & .06 & .27 & - \\
(6) Performance avoid goal orientation & -.15 & .03 & -.12 & .20 & .38 \\
\hline
\end{tabular}

Note. Listwise $n=990$. Correlation coefficients in bold are statistically significant at $p<.05$. 

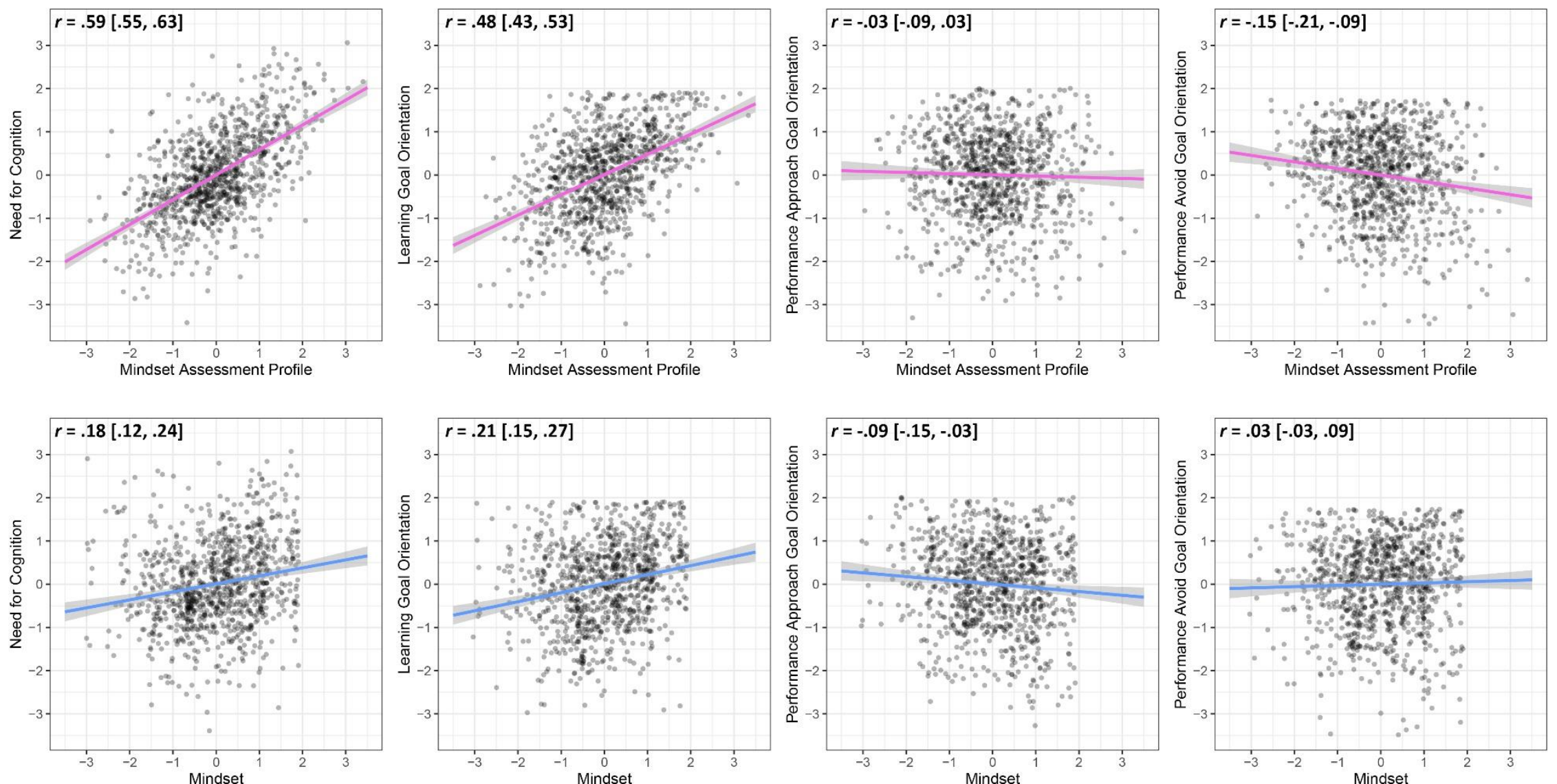

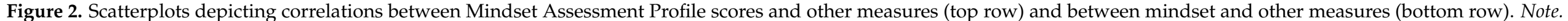
"Mindset" refers to the Implicit Theories of Intelligence Questionnaire. All scores are standardized (i.e., z-scores). 
Table 3. Correlations between items in the Mindset Assessment Profile and personality measures.

\begin{tabular}{|c|c|c|c|c|c|}
\hline Mindset Assessment Profile Item & Mindset & $\begin{array}{l}\text { Need for } \\
\text { Cognition }\end{array}$ & $\begin{array}{c}\text { Performance } \\
\text { Approach }\end{array}$ & $\begin{array}{l}\text { Performance } \\
\text { Avoidance }\end{array}$ & $\begin{array}{c}\text { Learning } \\
\text { Goal }\end{array}$ \\
\hline $\begin{array}{l}\text { (1) No matter how much intelligence you have, you can } \\
\text { always change it a good deal. }\end{array}$ & .70 & .10 & -.02 & .04 & .17 \\
\hline $\begin{array}{l}\text { (2) You can learn new things, but you cannot really } \\
\text { change your basic level of intelligence. }\end{array}$ & .71 & .14 & -.06 & .00 & .13 \\
\hline (3) I like my work best when it makes me think hard. & .14 & .57 & .13 & .01 & .50 \\
\hline $\begin{array}{l}\text { (4) I like my work best when I can do it really well } \\
\text { without too much trouble. }\end{array}$ & -.01 & .32 & -.04 & -.13 & .15 \\
\hline $\begin{array}{l}\text { (5) I like work that I'll learn from even if I make a lot } \\
\text { of mistakes. }\end{array}$ & .22 & .38 & -.02 & -.06 & .34 \\
\hline $\begin{array}{l}\text { (6) I like my work best when I can do it perfectly } \\
\text { without any mistakes. }\end{array}$ & -.01 & .22 & -.14 & -.21 & .09 \\
\hline $\begin{array}{l}\text { (7) When something is hard, it just makes me want to } \\
\text { work more on it, not less. }\end{array}$ & .12 & .43 & .06 & -.13 & .39 \\
\hline $\begin{array}{l}\text { (8) To tell the truth, when I work hard, it makes me feel } \\
\text { as though I'm not very smart. }\end{array}$ & .20 & .33 & .02 & -.12 & .28 \\
\hline
\end{tabular}

Note. Listwise $n=971$. The correlation coefficient in bold is the strongest correlation for each item. $|r \mathrm{~s}| \geq .07$ are statistically significant at $p<.05$.

\subsection{Factor Structure of the Mindset Assessment Profile}

Finally, we conducted an exploratory factor analysis on the items in the Mindset Assessment Profile to determine whether a single personality factor or multiple personality factors were underlying scores on this measure. We used principal axis factoring with promax rotation to allow extracted factors to correlate, and extracted factors with Eigenvalues $\geq 1.0$.

As shown in Table 4, three factors emerged from the exploratory factor analysis of the Mindset Assessment Profile. Items three, five, and seven had high loadings on the first factor; items one and two had high loadings on the second factor; and items four and six had high loadings on the third factor. Item eight did not load highly on any factor. Although subject to interpretation, the first factor appears to represent need for cognition, the second factor appears to represent mindset, and the third factor appears to represent performance goal orientation. These results suggest that the Mindset Assessment Profile is not a unidimensional measure of mindset, but rather that three factors underlie scores on this measure.

Table 4. Exploratory factor analysis of the Mindset Assessment Profile.

\begin{tabular}{|c|c|c|c|}
\hline Mindset Assessment Profile Item & Factor 1 & Factor 2 & Factor 3 \\
\hline (1) No matter how much intelligence you have, you can always change it a good deal. & .21 & .56 & -.22 \\
\hline (2) You can learn new things, but you cannot really change your basic level of intelligence. & -.12 & .87 & .12 \\
\hline (3) I like my work best when it makes me think hard. & .69 & -.04 & .05 \\
\hline (4) I like my work best when I can do it really well without too much trouble. & .03 & .00 & .72 \\
\hline (5) I like work that I'll learn from even if I make a lot of mistakes. & .62 & .02 & -.06 \\
\hline (6) I like my work best when I can do it perfectly without any mistakes. & .06 & .00 & .62 \\
\hline 7) When something is hard, it just makes me want to work more on it, not less. & .56 & -.01 & .09 \\
\hline (8) To tell the truth, when I work hard, it makes me feel as though I'm not very smart. & .25 & .16 & .09 \\
\hline Eigenvalue & 2.28 & 1.53 & 1.15 \\
\hline
\end{tabular}

Note. Listwise $n=973$. The coefficient in bold is the strongest factor loading for each item. Correlations between factors: Factor 1 with Factor $2(r=.26)$; Factor 1 with Factor $3(r=.25)$, Factor 2 with Factor $3(r=.00)$.

\section{Discussion}

We assessed the reliability, construct validity, and factor structure of the Mindset Assessment Profile in a sample of 992 undergraduate students. The internal reliability of the Mindset Assessment Profile $(\alpha=.63)$ was significantly lower than that of the Implicit 
Theories of Intelligence Questionnaire $(\alpha=.94)$, which had excellent reliability. Both of these measures consist of eight items and were ostensibly designed to measure mindset.

Further, the Mindset Assessment Profile lacked construct validity as a measure of mindset. Overall scores on the Mindset Assessment Profile correlated significantly more strongly with need for cognition than with mindset. Item-level analyses supported this finding, revealing that six of eight items in the Mindset Assessment Profile correlated more strongly with both need for cognition $(\bar{r}=.38)$ and learning goal orientation $(\bar{r}=.29)$ than with mindset $(\bar{r}=.12)$. Only two of eight items from the Mindset Assessment Profile correlated strongly with mindset $(r s=.70$ and .71$)$ as measured by the Implicit Theories of Intelligence Questionnaire. These items are nearly identical to items from the Implicit Theories of Intelligence Questionnaire. Finally, two of the eight items in the Mindset Assessment Profile had no association with mindset as measured by the Implicit Theories of Intelligence Questionnaire ( $r \mathrm{~s}=-.01, p \mathrm{~s}>.65$ ).

Exploratory factor analysis revealed that three factors were underlying scores on the Mindset Assessment Profile. These factors appeared to represent need for cognition, mindset, and performance goal orientation. This corroborates the previous results by showing that the Mindset Assessment Profile is not a unidimensional measure of mindset.

The Mindset Assessment Profile is marketed as a measure of mindset. That is, students are encouraged to use the Mindset Assessment Profile to "assess their mindsets" on the Mindset Works website (http:/ / blog.mindsetworks.com/what-s-my-mindset (accessed on 6 April 2021)). After completing the questionnaire, they are emailed a description of their "current mindset." Regardless of their results, they are directed to a webpage that sells growth mindset interventions ranging in cost from $\$ 20$ per student to $\$ 7500$ per school (https:/ / www.mindsetworks.com/programs/ (accessed on 6 April 2021)).

Perhaps of greater concern, the Mindset Assessment Profile is included as a diagnostic tool in some of Mindset Works' growth mindset intervention programs. If the Mindset Assessment Profile is administered before and after a mindset intervention, change scores might be taken as evidence that an intervention successfully altered a student's mindset, when this effect would be more accurately described as a change in need for cognition.

This tendency to misconstrue Mindset Assessment Profile scores is not uncommon. As a case in point, Bedford (2017) administered the Mindset Assessment Profile to secondary school students before and after a growth mindset intervention "to evaluate the success of the growth mindset interventions" (p. 433). When Bedford (2017) found significantly different Mindset Assessment Profile scores following the intervention, this was interpreted as evidence that the "interventions put in place were successful in changing mindset towards a growth mindset" (p. 436). As another example, Wolferd (2020) recently administered the Mindset Assessment Profile to elementary school children to evaluate the effects of Mindset Works' Brainology program. Based on their scores on the Mindset Assessment Profile following the intervention, they reported that "female students in the experimental group displayed a significant, positive change in mindset" (p. 49) suggesting that "Brainology was an effective intervention for female students" (Wolferd 2020, p. 51). The research presented herein suggests that the Mindset Assessment Profile is more a measure of need for cognition than mindset, and that its description as a "mindset" assessment has led to misunderstandings about the efficacy of mindset interventions.

Relatedly, Lim et al. (2020) recently used the Mindset Assessment Profile as a diagnostic tool to assess college students in a work-study program. Based on their scores on the Mindset Assessment Profile, students were categorized into those with a "growth mindset" and those with a "fixed or unsure mindset" (p. 111). They found that "growth mindset" students' work-study supervisors rated them more highly on problem solving and decision-making than students not categorized as having a "growth mindset." However, based on our research, a more accurate conclusion would be that students with higher need for cognition are more likely to be rated higher on problem solving and decision-making than students lower in need for cognition. 
In sum, despite the Mindset Assessment Profile's stated purpose as a mindset assessment and diagnostic tool, our results indicate that it is a poor measure of mindset. We recommend researchers avoid using the Mindset Assessment Profile as a measure of mindset or as a diagnostic tool in educational contexts.

Author Contributions: Conceptualization, A.P.B. and B.N.M.; methodology, A.P.B. and B.N.M.; software, A.P.B.; formal analysis, A.P.B.; investigation, A.P.B.; resources, A.P.B.; data curation, A.P.B.; writing - original draft preparation, A.P.B. and B.N.M.; writing—review and editing, A.P.B. and B.N.M.; visualization, A.P.B.; project administration, A.P.B. All authors have read and agreed to the published version of the manuscript.

Funding: This research received no external funding.

Institutional Review Board Statement: This research was approved by the Institutional Review Board at Michigan State University on 6 June 2016 (IRB numbers: x16-753e; i051494).

Informed Consent Statement: Informed consent was obtained from all subjects involved in the study.

Data Availability Statement: Data and preregistration are provided at the following Open Science Framework link: https:/ / osf.io/n82f4/?view_only=f236b81a4d434711aff5db4b26f319a8.

Conflicts of Interest: The authors declare that they have no conflict of interest to report for the present manuscript.

\section{Appendix A}

Table A1. Correlation matrix with all items from the Mindset Assessment Profile.

\begin{tabular}{|c|c|c|c|c|c|c|c|}
\hline Mindset Assessment Profile Item & 1 & 2 & 3 & 4 & 5 & 6 & 7 \\
\hline $\begin{array}{l}\text { (1) No matter how much intelligence you have, you can always change it a } \\
\text { good deal. }\end{array}$ & - & & & & & & \\
\hline $\begin{array}{l}\text { (2) You can learn new things, but you cannot really change your basic level of } \\
\text { intelligence. }\end{array}$ & .49 & - & & & & & \\
\hline (3) I like my work best when it makes me think hard. & .16 & .07 & - & & & & \\
\hline (4) I like my work best when I can do it really well without too much trouble. & -.09 & .07 & 20 & - & & & \\
\hline (5) I like work that I'll learn from even if I make a lot of mistakes. & .23 & .08 & 41 & .05 & - & & \\
\hline (6) I like my work best when I can do it perfectly without any mistakes. & -.10 & .07 & .15 & .47 & .15 & - & \\
\hline (7) When something is hard, it just makes me want to work more on it, not less. & .16 & .08 & .41 & .20 & .34 & .16 & - \\
\hline $\begin{array}{l}\text { (8) To tell the truth, when I work hard, it makes me feel as though I'm not } \\
\text { very smart. }\end{array}$ & .12 & .20 & .25 & .11 & .20 & .12 & .16 \\
\hline
\end{tabular}

Note. Listwise $n=973$. Correlations in bold are statistically significant at $p<.05$.

\section{Notes}

1 This analysis was not pre-registered.

\section{References}

Abd-El-Fattah, Sabry M., and Hala K. Hassan. 2011. Dependent-alpha calculator: Testing the differences between dependent coefficients Alpha. Journal of Applied Quantitative Methods 11: 59-61.

Bedford, Susannah. 2017. Growth mindset and motivation: A study into secondary school science learning. Research Papers in Education 32: 424-43. [CrossRef]

Birney, Damian P., Jens F. Beckmann, Nadin Beckmann, Kit S. Double, and Karen Whittingham. 2018. Moderators of learning and performance trajectories in microworld simulations: Too soon to give up on intellect!? Intelligence 68: 128-40. [CrossRef]

Blackwell, Lisa S., Kali H. Trzesniewski, and Carol Sorich Dweck. 2007. Implicit theories of intelligence predict achievement across an adolescent transition: A longitudinal study and an intervention. Child Development 78: 246-63. [CrossRef]

Boaler, Jo. 2013. Ability and mathematics: The mindset revolution that is reshaping education. Forum 55: 143-52. [CrossRef]

Burgoyne, Alexander P., David Z. Hambrick, and Brooke N. Macnamara. 2020. How firm are the foundations of mind-set theory? The claims appear stronger than the evidence. Psychological Science 31: 258-67. [CrossRef] [PubMed]

Cacioppo, John T., and Richard E. Petty. 1982. The need for cognition. Journal of Personality and Social Psychology 42: 116-31. [CrossRef] 
Cacioppo, John T., Richard E. Petty, and Chuan Feng Kao. 1984. The efficient assessment of need for cognition. Journal of Personality Assessment 48: 306-7. [CrossRef] [PubMed]

Campbell, Donald T., and Donald W. Fiske. 1959. Convergent and discriminant validation by the multitrait-multimethod matrix. Psychological Bulletin 56: 81-105. [CrossRef] [PubMed]

Cartwright, T. J., and B. Hallar. 2018. Taking risks with a growth mindset: Long-term influence of an elementary pre-service after school science practicum. International Journal of Science Education 40: 348-70. [CrossRef]

Cronbach, Lee J. 1951. Coefficient alpha and the internal structure of tests. Psychometrika 16: 297-334. [CrossRef]

Cunningham, William A., Kristopher J. Preacher, and Mahzarin R. Banaji. 2001. Implicit attitude measures: Consistency, stability, and convergent validity. Psychological Science 12: 163-70. [CrossRef] [PubMed]

Dweck, Carol S. 1986. Motivational processes affecting learning. American Psychologist 10: 1040-48. [CrossRef]

Dweck, Carol S. 2000. Self-Theories: Their Role in Motivation, Personality, and Development. East Sussex: Psychology Press.

Dweck, Carol S., and Ellen L. Leggett. 1988. A social-cognitive approach to motivation and personality. Psychological Review 95: 256-73. [CrossRef]

Elliot, Andrew J., and Marcy A. Church. 1997. A hierarchical model of approach and avoidance achievement motivation. Journal of Personality and Social Psychology 72: 218-32. [CrossRef]

Faul, Franz, Edgar Erdfelder, Albert-Georg Lang, and Axel Buchner. 2007. G* Power 3: A flexible statistical power analysis program for the social, behavioral, and biomedical sciences. Behavior Research Methods 39: 175-91. [CrossRef] [PubMed]

George, Darren, and Paul Mallery. 2003. SPSS for Windows Step by Step: A Simple Guide and Reference, 11.0 update 4th ed. Boston: Allyn \& Bacon.

Hall, Charity. 2016. Mindset and Instructional Practices in the Elementary Mathematics Classroom. (4121.). Master's Thesis, School of Education Student Capstone Theses and Dissertation, Saint Paul, MN, USA. Available online: https://digitalcommons.hamline. edu/hse_all/4121 (accessed on 6 April 2021).

Li, Yue, and Timothy C. Bates. 2019. You can't change your basic ability, but you work at things, and that's how we get hard things done: Testing the role of growth mindset on response to setbacks, educational attainment, and cognitive ability. Journal of Experimental Psychology: General 148: 1640-55. [CrossRef] [PubMed]

Lim, Sok Mui, Yong Lim Foo, May-Fung Yeo, Chelsea Yu Xian Chan, and Han Tong Loh. 2020. Integrated work study program: Students' growth mindset and perception of change in work-related skills. International Journal of Work-Integrated Learning 21: 103-15.

McDonald, Roderick P. 1999. Test Theory: A Unified Treatment. Mahwah: Lawrence Erlbaum.

McNeish, Daniel. 2018. Thanks coefficient alpha, we'll take it from here. Psychological Methods 23: 412-33. [CrossRef] [PubMed]

Neufville, Merica E. 2019. Perspectives of Mathematically Proficient Black High School Students with a History of Underachievement in Mathematics. Ph.D. thesis, St. John Fisher College, Rochester, NY, USA. Available online: https:/ / fisherpub.sjfc.edu/education_ etd/420/ (accessed on 6 April 2021).

O'Leary-Kelly, Scott W., and Robert J. Vokurka. 1998. The empirical assessment of construct validity. Journal of Operations Management 16: 387-405. [CrossRef]

Payne, Stephanie C., Satoris S. Youngcourt, and J. Matthew Beaubien. 2007. A meta-analytic examination of the goal orientation nomological net. Journal of Applied Psychology 92: 128-50. [CrossRef] [PubMed]

Saia, Katherine. 2017. Impact of Mindset on Literacy: What Happens to Literacy Skills When a Growth Mindset Is Taught to First Graders. (2346). Master's Thesis, Rowan University, Glassboro, NJ, USA. Available online: https://rdw.rowan.edu/etd/2346 (accessed on 6 April 2021).

Sisk, Victoria F., Alexander P. Burgoyne, Jingze Sun, Jennifer L. Butler, and Brooke N. Macnamara. 2018. To what extent and under which circumstances are growth mind-sets important to academic achievement? Two meta-analyses. Psychological Science 29: 549-71. [CrossRef] [PubMed]

Steiger, James H. 1980. Tests for comparing elements of a correlation matrix. Psychological Bulletin 87: 245-51. [CrossRef]

Thomas, Phillip. 2018. The Impact of Teaching Growth Mindset on Archery Skill Achievement: An Action Research Study. Ph.D. thesis, University of South Carolina, Columbia, SC, USA. Available online: https:/ / scholarcommons.sc.edu/etd/5101 (accessed on 6 April 2021).

Wakefield, Maria C. 2019. An Examination of Mindset and Academic Growth of Middle School Science Students. Ph.D. thesis, Regent University, Virginia Beach, VA, USA. Available online: https://search.proquest.com/docview /2248012392?pq-origsite= gscholar\&fromopenview=true (accessed on 6 April 2021).

Wolferd, Jaclyn N. 2020. A Growth Mindset Intervention with Elementary-Age Children. Ph.D. thesis, Alfred University, Alfred, NY, USA. Available online: https:/ / aura.alfred.edu/bitstream/handle/10829/23571/Wolferd_Jaclyn_2020.pdf (accessed on 6 April 2021).

Zinbarg, Richard E., William Revelle, Iftah Yovel, and Wen Li. 2005. Cronbach's $\alpha$, Revelle's $\beta$, and McDonald's $\omega$ H: Their relations with each other and two alternative conceptualizations of reliability. Psychometrika 70: 123-33. [CrossRef] 